\title{
Periodontal Disease and COPD
}

\author{
Swarga Jyoti Das* \\ Department of Periodontics and Implantology, Regional Dental College, India
}

*Corresponding author: Swarga Jyoti Das, Professor, Department of Periodontics and Implantology, Regional Dental College, Guwahati 781032, Assam, India

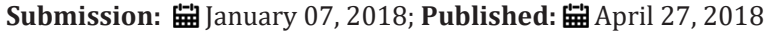

\section{Introduction}

Periodontal disease is an inflammatory disease caused predominantly by Gram-negative, anaerobic, and microaerophilic bacteria that colonise the subgingival area though modified by environment, physical, social and host stresses. It results in progressive destruction of the periodontal ligament and alveolar bone with increased probing depth, recession, or both [1]. Throughout the history of mankind, it has been believed that oral diseases and maladies including periodontal disease may have an effect on the rest of the body. Over the centuries, writings from the ancient Egyptians, Hebrews, Assyrians, Greeks and Romans, have all noted the importance of the mouth in overall health and well-being. Thus, the concept of linking periodontitis and systemic diseases could be traced back to the beginning of recorded history and medicine [2].

Periodontal disease has been linked to an increased risk of various systemic diseases, including the respiratory diseases e.g. pneumonia and chronic obstructive pulmonary disease (COPD) [3]. COPD is a generic term defined by the presence of airflow obstruction with excess production of sputum resulting from chronic bronchitis and/or emphysema. It has been recognized as one of the major causes of death and disability globally and is the fourth leading cause of death in United States [4]. The aetiology of COPD is complex and multifactorial, involving multiple genetic and environmental factors [5]. An enhanced or abnormal inflammatory response to inhaled particles or gases, beyond the normal protective inflammatory response in the lungs, is a characteristic feature of COPD and is potential to produce lung injury [6].

In individuals with periodontitis, bacteria present in the gingival sulcus or the subsequently formed periodontal pockets, may have easy access to the blood vessels [7]. Again aspiration of oropharyngeal secretions involving the pathogens present in dental plaque is well-documented cause of COPD. Therefore, it is plausible that oral microorganisms might infect the respiratory tract, causing COPD $[8,9]$.

Since both the COPD and periodontal disease are inflammatory in nature and the tissue damages occur in both are the result of major inflammatory components (e.g. prostaglandins and cytokines) activated by the host response. Therefore, it is possible that both the disease may have a linking mechanism. Parallel mechanisms for the development of both conditions are given by Travis et al. [10] (Figure 1).

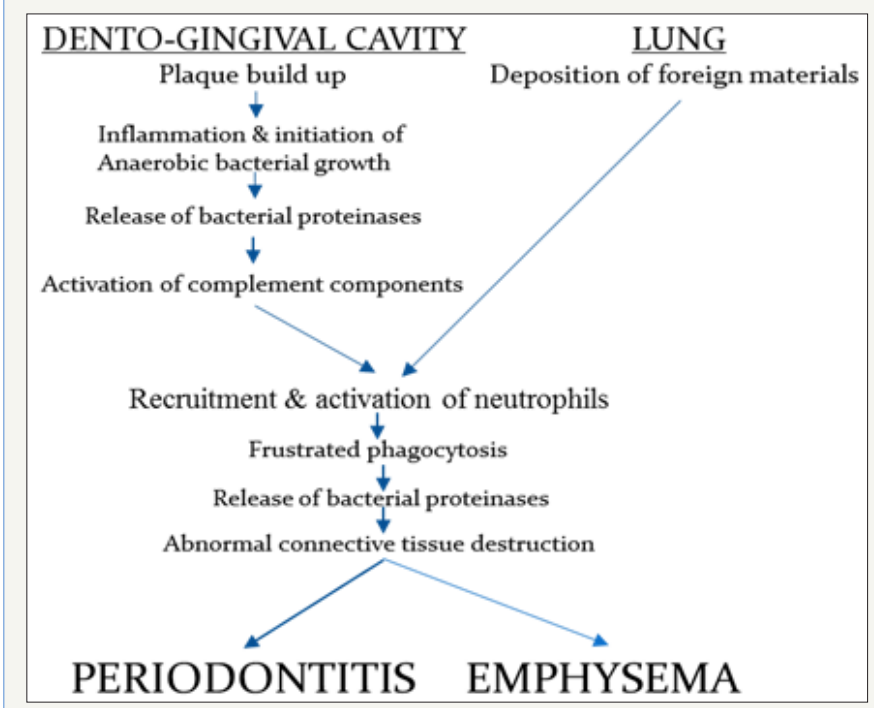

Figure 1: Parallel mechanisms in the development of emphysema and periodontitis [10].

Again, nearly half of COPD patients are accounted a limitation in daily activities and reduced quality of life. They are in trouble to perform their regular activities and subsequently, leading to depression and hopelessness. Therefore, the goal of COPD therapy should not only be to improve the physiological and functional state, but also to minimize the impact of the disease on the patients' quality of life. Wang et al. [11] noted a positive and important role of promotion of oral health knowledge and dental care on the prevention and treatment of COPD.

It has been understood that poor oral health (periodontitis) alone is not responsible for COPD, rather poor oral health may work as an adjunct with other factors, namely continued smoking, environmental pollutants, viral infections, allergies and/or genetic factors to promote the progression and/or exacerbation 
of COPD. Both chronic periodontitis and COPD are neutrophilic, inflammatory conditions characterized by the loss of local connective tissue. Evidence suggests an association and perhaps a causal link between the two diseases [12], though the nature of any relationship between them is unclear. However, if it is established pathophysiologically, it may help both the dental and medical professionals to determine the best approach to patient care in terms of targeted treatments to improve outcomes and prognosis. Thus, it marks a beginning of new era in periodontics and provides an opportunity for dental surgeons to develop new relationships with physician colleagues. Dental surgeons should be encouraged to communicate with physicians about the health of their patients, and physicians should be alerted to the possible risks of severe periodontitis.

In addition, periodontal disease, if confirmed, as a risk factor for various systemic diseases will be very valuable, since periodontal disease can be controlled, treated or prevented. Thus, it appears that teeth are not just at stake in maintaining good oral health. Rather, oral health is an important component of general health. It is thus, clear that prevention and treatment of periodontal disease are necessary to maintain periodontal health; without periodontal health, general health is often compromised.

\section{References}

1. Newman MG, Takei HH, Klokkevold PR (2011) Carranza's Clinical Periododontology. PA Saunders, Philadelphia, USA, pp. 228-499.

2. Lindhe J, Karring T, Niklaus P (2003) Textbook of Clinical Peridontology and Implant Dentistry. Blackwell Munksgaard. pp. 366-381
3. Fowler EB, Breault LG, Cuenin MF (2011) Periodontal disease and its association with systemic disease. Mil Med 166(1): 85-89.

4. Viegi G, Scognamiglio A, Baldacci S, Pistelli F, Carrozzi L (2001) Epidemiology of chronic obstructive pulmonary disease (COPD). Respirology 68(1): 4-19.

5. Rabe KF, Hurd S, Anzueto A, Barnes PJ, Buist SA, et al. (2007) Global strategy for the diagnosis, management, and prevention of chronic obstructive pulmonary disease: GOLD executive summary. Am J Respir and Crit Care Med 176(6): 532-555.

6. Saetta M (1999) Airway inflammation in chronic obstructive pulmonary disease. Am J Respir Crit Care Med 160(Suppl 1): S17-S20.

7. Thoden V, Abraham IL, Moorer WR (1984) Plaque and systemic disease: A reappraisal of the focal infection concept. J Clin Periodontol 11(4): 209-220.

8. Scannapieco FA (1999) Role of Oral bacteria in respiratory infection. J Periodontol 70: 793-802.

9. Scannapieco FA, Ho AW (2001) Potential associations between chronic respiratory disease and periodontal disease: Analysis of national health and nutrition examination survey III. J Periodontol 72(1): 50-56.

10. Travis J, Pike R, Imamura T, Potempa J (1994) The role of proteolytic enzymes in the development of pulmonary emphysema and periodontal disease. Am J Respir Crit Care Med 150(6 Pt 2): S143-S146.

11. Wang Z, Zhou X, Zhang J, Zhang L, Song Y, et al. (2009) Periodontal health, oral health behaviours, and chronic obstructive pulmonary disease. J Clin Periodontol 36(9): 750-755.

12. Garcia RI, Nunn ME, Vokonas PS (2001) Epidemiologic associations between periodontal disease and chronic obstructive pulmonary disease. Ann Periodontol 6(1): 71-77.
Creative Commons Attribution 4.0

International License

For possible submissions Click Here

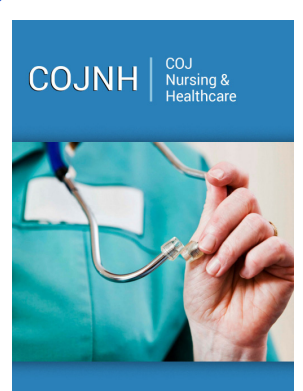

\section{COJ Nursing \& Healthcare}

\section{Benefits of Publishing with us}

- High-level peer review and editorial services

- Freely accessible online immediately upon publication

- Authors retain the copyright to their work

- Licensing it under a Creative Commons license

- Visibility through different online platforms 